\title{
Disorientasi Makna Jihad Dalam Komik Jihad Selfie (Analisis Semiotika Roland Barthes)
}

\author{
Ivan Sunata \\ Institut Agama Islam Negeri (IAIN) Kerinci \\ ivansunata.ma@gmail.com
}

\begin{abstract}
This study raises a true story of the life of an Indonesian student studying at Imam Katip High School in Turkey, namely Teuku Akbar Maulana. One day a heavy temptation arose and almost changed the course of his life. He almost joined the Islamic State of Iraq and Syria (ISIS) in Syria, following in his friend's footsteps. One factor in his interest in joining ISIS is propaganda on social media in the form of showing ISIS members holding and using weapons. On that basis, Teuku Akbar Maulana perceives that jihad is identical with weapons and so on. Therefore, this research will reveal some of the mistakes of Teuku Akbar and other Indonesian students in understanding the true meaning of jihad.The purpose of this study is to uncover the forms of disorientation of the meaning of jihad contained in the selfie jihad comics. The type of research used is qualitative, which is a method for obtaining an objective picture of the variables studied, the conclusion being predetermined. Qualitative research is often called naturalistic research because the research is conducted in natural conditions. The approach used is Roland Barthes's semiotics. Semiotics is the science of signs. Semiotics can be defined as the study of a wide range of objects, events, and all cultures as signs (Sobur, 2004, p. 95). Whereas the sign is defined as something that is based on conventional social previously developed, can be considered to represent something else. Semiotics can be used to examine various texts. The text here is media content that appears in any form, such as television shows, newspaper news, music concerts, films, advertisements, fashion, fiction, poetry, and drama (Sobur, 2004, p. 14).To obtain the data needed in this study, the researchers used the documentation method. According to (Arikunto, 2002), the documentation method is a method used by finding data about things or variables in the form of notes, transcripts, books, newspapers, magazines, inscriptions, documents, minutes of meetings, agendas, and so on ( $p$. 231).Then the authors analyze the word for word, sentence by sentence, and
\end{abstract}

\author{
Jurnal Dakwah dan Komunikasi \\ IAIN Curup | E-ISSN 2548-3366 ; P- ISSN 2548-3293
}


discourse contained in the Jihad Selfie comics. The analysis in this study are texts relating to the disorientation of the meaning of jihad contained in the Jihad Selfie comics. The steps of analysis that will be carried out by researchers are describing the data needed from the Jihad Selfie comics. Then, the data in the form of text is read qualitatively descriptive. The signs used in the comics will then be interpreted in accordance with the disorientation of the meaning of jihad, so that the meaning of the novel can be understood both at the first level (denotative), and at the second level (connotative).In general, the results of the study showed that there was a disorientation in the meaning of jihad in Teuku Akbar Maulana and other Indonesian students who joined ISIS. Some forms of deviation from the meaning of jihad are as follows; (1) Jihad is identical to weapons, (2) By holding a weapon and other military attributes it will look like a member of the TNI even more handsome than a member of the TNI (3) Jihad can bring the perpetrators around the cities in the Middle East, (4) There are various facilities that luxury for the mujahid.

Keywords: disorientation of meaning, Selfie jihad comics

\section{Abstrak}

Penelitian ini mengangkat sebuah kisah nyata kehidupan seorang mahasiswa Indonesia yang kuliah Imam Katip High School di Turki, yakni Teuku Akbar Maulana. Suatu hari godaan berat muncul dan hampir mengubah jalan hidupnya. Ia nyaris bergabung dengan Negara Islam Irak dan Suriah (ISIS) di Suriah, mengikuti jejak temannya.Salah satu faktor ketertarikannya bergabung dengan ISIS adalah propaganda di media sosial berupa penayangan anggota ISIS memegang dan menggunakan senjata.Atas dasar itu, Teuku Akbar Maulana mempersepsikan bahwa jihad itu identik dengan senjata dan sebagainya.Oleh karena itu, penelitian ini akan mengungkapkan beberapa kesalahan Teuku Akbar dan pelajar Indonesia lainnya dalam memahami makna jihad sesungguhnya.Tujuan penelitian ini untuk mengungkap bentukbentuk disorientasi makna jihad yang terkandung pada komik jihad selfie. Jenis penelitian yang digunakan kualitatif, yaitu suatu metode untuk mendapatkan gambaran yang objektif terhadap variabel yang diteliti yang kesimpulannya berupa prediket. Penelitian kualitatif sering disebut penelitian naturalistik karena penelitiannya dilakukan pada kondisi yang alamiah (natural setting). Pendekatan yang digunakan adalah semiotika Roland Barthes.Semiotik adalah ilmu tentang tanda-tanda. Semiotik dapat didefinisikan sebagai ilmu yang mempelajari sederetan luas objek- 
objek, peristiwa-peristiwa, dan seluruh kebudayaan sebagai tanda. ${ }^{1}$ Sedangkan tanda didefinisikan sebagai sesuatu yang atas dasar konvensional sosial yang terbangun sebelumnya, dapat dianggap mewakili sesuatu yang lain. Semiotik dapat digunakan untuk meneliti bermacam-macam teks. Teks disini adalah isi media yang tampil dalam wujud apa saja, seperti tayangan televisi, berita surat kabar, konser musik, film, iklan, fasion, fiksi, puisi, dan drama. ${ }^{2}$ Untuk memperoleh data yang diperlukan dalam penelitian ini, maka peneliti menggunakan metode dokumentasi. Metode dokumentasi adalah metode yang digunakan dengan cara mencari data mengenai hal-hal atau variabel yang berupa catatan, transkrip, buku, surat kabar, majalah, prasasti, dokumen, notulen rapat, agenda, dan sebagainya. ${ }^{3}$ Kemudian penulis menganalisis kata demi kata, kalimat demi kalimat, dan wacana yang terdapat pada komikJihad Selfie. Analisis dalam penelitian ini adalah teks-teks yang berkaitan dengan disorientasi makna jihad yang terdapat di dalam komik Jihad Selfie. Langkah-langkah analisis yang akan dilakukan peneliti adalah mendeskripsikan data yang diperlukan dari komik Jihad Selfie. Kemudian, data yang berupa teks tersebut dibaca secara kualitatif deskriptif. Tanda yang digunakan dalam komik lalu akan diinterpretasikan sesuai dengan disorientasi makna jihad, sehingga makna novel akan dapat dipahami baik pada tataran pertama (denotatif), maupun pada tataran kedua (konotatif). Secara umum hasil penelitian menunjukkan bahwa terdapat disorientasi makna jihad pada diri Teuku Akbar Maulana dan pelajar-pelajar Indonesia lainnya yang bergabung dengan ISIS. Beberapa bentuk penyimpangan makna jihad diantaranya sebagai berikut; (1) Jihad identik dengan senjata, (2) Dengan memegang senjata dan atribut militer lainnya akan terlihat seperti anggota TNI bahkan legih gagah dari anggotaTNI (3) Jihad bisa membawa pelakunya mengelilingi kota-kota di Timur Tengah, (4) Terdapat berbagai fasilitas yang mewah bagi para mujahid.

Kata Kunci:Disorientasi Makna Jihad, Komik Jihad Selfie

\footnotetext{
${ }^{1}$ Alex Sobur, Analisis Teks Media, (Bandung: Remaja Rosdakarya, 2004), 95

${ }^{2}$ Ibid., 14

3 Suharsimi Arikunto, Prosedur Penelitian Suatu Pendekatan Praktek,
} (Jakarta: Rineka Cipta, 2002), 231 


\section{Pendahuluan}

Komik jihad selfie menceritakan tentang sosok seorang pria bernama Teuku Akbar Maulana seorang remaja brilian yang hafal Al-Qur'an dan mahir berbahasa Arab, mendapat beasiswa dari pemerintah Turki untuk belajar agama di Imam Katip High School, setara dengan Madrasah Aliyah di Indonesia.Namun, dari kota di Anatolia Tengah itu, sebuah godaan berat muncul dan hampir mengubah jalan hidupnya dari seorang calon imam dan khatib. Ia nyaris meninggalkan keluarganya di Aceh dan bergabung dengan Negara Islam Irak dan Suriah (ISIS) di Suriah, mengikuti jejak temannya.

Di laman Facebook, Akbar melihat foto Yazid, seorang teman satu asrama dari Indonesia, yang lebih dulu bergabung menjadi pejuang ISIS, tampak gagah memegang senapan AK 47. Ternyata Yazid juga telah merekrut Bagus, teman lain asal Indonesia yang juga sedang belajar di Turki.

Film ini mengangkat sebuah fenomena tentang pola baru perekrutan pejuang ISIS dengan sasaran remaja belasan tahun melalui media sosial.Berbeda dengan pola lama, di mana individu lebih dulu bergabung dengan kelompok kekerasan kemudian melakukan aksi terorisme, pola baru ini melibatkan peran internet dan media sosial.

Individu, terutama remaja, mengakses internet dan mengetahui peristiwa konflik Timur Tengah, kemudian menjalin komunikasi dengan jaringan pelaku sebelum akhirnya terlibat dalam aksi kekerasan, seperti bom bunuh diri.Media sosial telah mengubah pendukung pasif menjadi pendukung aktif.

Adapun alasan peneliti memilih karya sastra komik sebagai obyek kajian didasarkan pada komik yang merupakan produk kebudayaan kontemporer, media ini sifatnya ringan, artinya materinya tidak terlalu berat, menghibur, populer, mudah dipahami dalam artian isi cerita tergantung pada keluwesan penulisannya serta sangat potensial sekali untuk digunakan sebagai media komunikasi untuk menyebarkan nilai-nilai humanisme dalam kehidupan kepada para penikmat novel.

Maka dari latar belakang yang telah dipaparkan di atas, maka penting untuk dilakukan penelitian guna mengetahui lebih jauh disorientasi makna jihad dalam komik Jihad Selfiekarya Noor Huda Ismail dengan kajian semiotika Roland Barthes.

\section{Hasil dan Pembahasan}

\section{Disorientasi Makna}

Disorientasi berasal dari dua kata yaitu dis yang berarti adanya masalah, gangguan, atau kegagalan dan orientasi. Orientasi sendiri bisa kita lihat dalam kamus inggris: Orientation is a function of the mind involving awareness of three dimensions: time, place and person. Dimensi itu bisa saja bertambah panjang dan komplek.Sedangkan kegagalan atau masalah itu bisa 
bersifat partial, spatial maupun total. ${ }^{4}$ Orang sering menghubungkan disorientasi ini dengan "kebingungan".Kebingungan adalah gejala, dan dapat berkisar dari ringan sampai parah.Seseorang yang bingung mungkin mengalami kesulitan memecahkan masalah.Gampang mengantuk, hiperaktif, atau cemas adalah tanda-tanda awal.Pada kasus yang parah, orang mungkin memiliki halusinasi, perasaan paranoia, dan keadaan delirium (mengigau).

Kebingungan tingkat patologis biasanya mengacu pada kehilangan orientasi (kemampuan untuk menempatkan diri dengan benar di dunia dengan waktu, lokasi, dan identitas pribadi) dan sering mengganggu memori (kemampuan untuk benar mengingat peristiwa-peristiwa sebelumnya atau belajar pada sesuatu atau materi yang baru). Kebingungan seperti itu tidak sama dengan ketidakmampuan untuk memusatkan perhatian.

Dalam ruang lingkup sejarah, disorientasi berakar pada kekacauan pola pikir historis yang menimbulkan hal-hal seperti anakronisme, generalisasi, distorsi semantik dan kebingungan substantif. ${ }^{5}$ Dari empat hal tersebut, penulis dalam melakukan penelitian ini memfokuskan pada teori distorsi semantik.

Secara bahasa distrosi memiliki arti penyimpangan, pemutarbalikan suatu fakta, aturandan sebagainya.Sedangkan secara istilah, distori semantik adalah perubahan makna atau arti dari suatu informasi/pesan yang secara sengaja mau pun tidak sengaja akan mengubah isi informasi. Atau bisa juga disebut kekurangtepatan atau perbedaan arti diantara pesan/informasi yang dikirim dalam suatu proses komunikasi. ${ }^{6}$

Gangguan semantik dalam komunikasi merupakan jenis gangguan yang seringkali terjadi dan menyebabkan proses komunikasi menjadi kurang efektif. Pada dasarnya, gangguan semantik terjadi akibat kesalahpahaman yang disebabkan oleh penggunaan bahasa atau gangguan makna dari kata yang ada. Gangguan semantik ini bisa menyebabkan informasi yang disampaikan menjadi salah makna. Akibatnya jelas, proses komunikasi tidak berjalan dengan semestinya dan menyebabkan makna dari komunikasi tersebut hilang. Tak hanya itu saja, gangguan semantik bila tidak dilakukan klarifikasi bahkan bisa menyebabkan perselisihan atau konflik. ${ }^{7}$

Oleh karenanya, penting bagi kita untuk mulai memahami apa saja gangguan semantik yang mungkin bisa saja muncul dalam proses komunikasi. Berikut ini adalah ulasan mengenai macam dari gangguan semantik tersebut: ${ }^{8}$

${ }^{4}$ Disorientasi Pemikiran, 2014, dalam https://www.abualbanicentre.com, diakses 14 September 2018

${ }^{5}$ Bambang Purwanto, Sejarawan Akademik dan Disorientasi Historiografi:

Sebuah Otokritik. (Dipresentasikan pada Rapat Terbuka Majelis Guru Besar Universitas Gadjah Mada, Yogyakarta, 2004, 5

${ }^{6}$ Abdul Karim Batubara, (2015) Distorsi Pesan dalam Perpustakaan. (Iqra': Jurnal Perpustakaan dan Informasi, 9(2), 2015, 2-3

${ }^{78}$ Gangguan Semantik dalam Komunikasi, 2018 dalam https://pakarkomunikasi.com, diakses pada 18 Agustus 2019

${ }^{8}$ Ibid. 
Adapun gangguan semantic yang pertama adalah allnessmerupakan istilah yang merujuk pada gangguan semantik dalam komunikasi yang menggambarkan bagaimana seseorang merasa sudah memahami semua informasi yang telah diberikan kepadanya oleh orang lain. Ia kemudian menumbuhkan suatu kepercayaan dari abstraksi yang sudah ia proyeksikan sebagai pembenaran dari informasi yang telah ia dapatkan. Allness ini biasanya cenderung menjadi sebuah kebiasaan sehingga seseorang mungkin akan sering menganggap paham padahal belum tentu pesan yang disampaikan sesuai dengan yang dipahami.

Kedua adalah kecenderungan untuk mengevaluasi dari proses komunikasi adalah bentuk gangguan semantik yang juga sering terjadi. Seseorang mungkin akan terfokus untuk menolak pendapat orang lain dan lebih cenderung memberikan evaluasi ketimbang menerima masukan atau informasi baru. Ini adalah bentuk gangguan semantik yang juga berasal dari kebiasaan.

Ketiga bypassingatau biasa disingkat sebagai BP adalah gangguan semantik yang cenderung menyalahkan orang lain. Tindakan menyalahkan orang lain ini terjadi terutama dalam rangka menyalahkan penggunaan kata yang menurutnya tidak pantas atau tidak tepat digunakan untuk merepresentasikan sesuatu, padahal sebenarnya itu adalah variasi bahasa yang ada. BP bisa menjadi hambatan komunikasi antar pribadi.

Keempat adalah kesalahan penggunaan bahasa merupakan gangguan semantik yang paling umum terjadi. Hambatan ini terjadi terutama ketika seseorang salah dalam menggunakan istilah tertentu. Terlalu banyak dalam menggunakan istilah-istilah asing mungkin kurang baik dan bisa menimbulkan hambatan komunikasi semacam ini. Gangguan bahasa dalam komunikasi ini umum terjadi.

Kelima adalah penilaian spontanitas mengandung makna bahwa seseorang akan memberikan pendapatnya begitu menerima informasi baru tanpa mencernanya dengan baik terlebih dahulu. Sebuah makna kiasan akan dianggap sebagai makna yang lugas. Ini akan memicu terjadinya gangguan semantik yang bahkan bisa menimbulkan perpecahan.

Keenam adalah kebingungan faktaBanyaknya informasi yang diterima akan menyebabkan kebingungan fakta. Informasi yang tidak konsisten terutama akan memberikan kesalahan-kesalahan dalam penerimaan komunikasi yang ada. Seseorang akan mengalami kebingungan mana yang fakta dan mana yang sebenarnya sesuatu yang kurang penting. Pembiasan ini akan menjadi faktor penyebab distorsi dalam komunikasi.

Ketujuh adalah pembuatan kesimpulan mentahMirip-mirip dengan penilaian spontanitas, informasi yang diterima seringkali tidak dicerna baikbaik sehingga akan timbul pembuatan kesimpulan yang mentah. Hasil kesimpulan mentah ini bila kemudian dipercaya banyak orang akan menjadi gangguan semantik dalam komunikasi. Komunikasi tidak berjalan dengan semestinya dan tidak sesuai dengan tujuan awal. (Baca juga: model komunikasi linear). 
Terakhir adalah tentang kesalahan persepsi yang bisa terjadi akibat akumulasi dari gangguan semantik di atas. Kesalahan persepsi akan memicu terjadinya konflik pada pihak yang terlibat di dalam komunikasi. Oleh karenanya, penting bagi kita untuk menghindari gangguan semantik dalam komunikasi agar tidak terjadi konflik atau pun perselisihan.

\section{Jihad}

Secara etimologi, jihad berasal dari kata kerja jâhada-yujâhidu, masdarnya jihâdan wa mujâhadatan. Dalam Lisan al-'Arab, Ibnu Mandzur menjelaskan bahwa jihad berasal dari kata al-juhd artinya al-tâqah (kekuatan), al-wus'u (usaha) dan al-masyaqqah (kesulitan). ${ }^{9}$ Pendapat Ibnu Mandzur ini senada dengan Muhammad Murtadha al-Husni al-Zabidi dalam Tâju al-'Arus, namun sedikit berbeda dengan Muhammad bin Abi Bakar bin 'Abdi al-Qadir alRazi dalam Mukhtar al-Shahâh yang menyebutkan jihad berasal dari kata al-juhd artinya al-tâqah, atau al-jahd artinya al-masyaqqah. Dengan demikian, asal kata jihad adalah al-jahdu dengan men-fathah-kan huruf jîm atau $a l$-juhdu dengan men-dhammah-kan huruf jîm, yang artinya $a l$ tâqah (kekuatan), al-wus'u (usaha) dan al-masyaqqah (kesulitan).

Selanjutnya, kata al-juhdu bermetamorfosa menjadi jihad. Jihad dalam kamus Mukhtar al-Shahah adalah badzlu al-wus' $i$ (mengerahkan kemampuan). Sementara dalam kamus Tâju al- 'Arus terdapat dua pengertian tentang jihad: (1) al-qitâlu ma'a al- 'aduwwi, kal mujâhadah (memerangi musuh seperti bermujahadah) dan (2) muhârabatu al-a'dâ', wa huwa almubâlaghah wa istifrâghu mâ fî al-wus'i wa al-tâqati min qawlin aw fi'lin. Wa almurâd bi al-niyyah ikhlash al-'amal lillâhi ta'ala (memerangi musuh dengan penuh kesungguhan dan kekuatan, baik berupa perkataan atau perbuatan, dengan niat ikhlas karena Allah SWT). Adapun dalam Lisânu al'Arab tertulis, jihad adalah qâtala wa jâhada fì sabîlillah (berperang dan berjuang di jalan Allah). Dari pemaparan tentang ta'rîf jihad di atas, maka dapat disimpulkan bahwa secara etimologi jihad adalah perjuangan dengan mengerahkan segenap kemampuan, baik perjuangan dalam bentuk melawan musuh di medan pertempuran, atau perjuangan tanpa terjun ke medan pertempuran. Sehingga muslim yang berjuang dengan menuntut ilmu kemudian berdakwah di jalan Allah SWT, sudah termasuk mujâhid (pelaku jihad).

Sementara dari sisi terminologi jihad memiliki makna yang beragam. Menurut Lembaga Riset Bahasa Arab Republik ArabMesir dalam al-Mu'jam al-Wasîth, jihad adalah qitâlun man laisa lahu dhimmatun min al-kuffâr (memerangi orang kafir yang tidak ada ikatan perjanjian damai). Pengertian ini terlihat lebih mengkhususkan kepada makna jihad perang. Dalam kamus Mu'jam al-Mushthalahât wa al-Fâdz al-Fiqhiyyah, Abdurrahman Abdul

${ }^{9}$ Rif'at Husnul Ma'afi, Konsep Jihad Dalam Perspektif Islam. (Kalimah: Jurnal Studi Agama dan Pemikiran Islam, 11(1), 2013,135 
Mun'im menulis pengertian jihad menjadi empat: (1) mengerahkan segenap kemampuan dalam memerangi orang kafir, (2) berjuang dari keragu-raguan dan godaan syahwat yang dibawa oleh setan, (3) berjuang dengan keyakinan yang teguh disertai dengan usaha yang sungguh-sungguh dengan cara mengajak kepada yang ma'ruf dan meninggalkan kemungkaran terhadap orang-orang fasik, dan (4) dalam makna serupa dengan pengertian yang ketiga, namun lebih khusus lagi yaitu terhadap orang-orang kafir yang memerangi umat Islam. Darinya dapat dipahami bahwa pengertian jihad tidak sekadar berperang di medan pertempuran, namun lebih luas dari itu. Sementara menurut Abdurrahman bin Hamad Ali Imran, jihad terbagi dua, umum dan khusus. Dalam pengertian umum, jihad adalah seorang muslim bersungguh-sungguh dalam menggapai sesuatu yang bisa mendekatkan dirinya kepada Allah SWT, serta menjauhkan diri dari apa saja yang dilarang oleh-Nya. Sedangkan dalam pengertian khusus adalah memerangi kaum kafir dalam rangka menegakkan kalimatullah (syariat Allah SWT).Definisi yang diberikan Abdurrahman ini menunjukkan bahwa pengertian jihad secara umum adalah segala perbuatan seorang muslim yang dilakukan dengan segenap kemampuan dan kesungguhannya untuk mencapai ridha Allah. Di sini juga dapat dipahami bahwa hanya pengertian secara khususlah yang berkonotasi perang di medan pertempuran yang tentu saja membutuhkan syarat-syarat khusus juga untuk merealisasikannya.

Dari pemaparan di atas terlihat bahwa pengertian jihad dari segi terminologi tidak jauh berbeda antara satu pendapat denganyang lainnya. Perbedaannya terletak pada luas sempitnya definisi yang diberikan. Dalam arti yang sempit (khusus), jihad berperang melawan orang kafir di medan pertempuran. Sementara dalam arti yang luas (umum) ia berarti kesungguhan seorang muslim dalam beribadah yang niatnya untuk mencapai ridha Allah SWT.

\section{Komik}

Komik merupakan kata serapan dari bahasa inggris comic yang diartikan sebagai istilah yang merupakan perwujudan sastra gambar. ${ }^{10}$ Pengertian tentang komik juga dikemukakanoleh Toni Masdiono,menurutnyakomik merupakan susunan gambar bercerita danmemberikan pesan-pesan pembacanya $^{11}$. Selanjutnya seorang komikus nasional, Koen mengatakan komik secara keseluruhan merupakan imaji kisah yang utuh hasil perkawinan gambar dan tulisan, dan secara parsial komik merupakan penekanan

${ }^{10}$ Dwi Nugroho Mukti, Salamun, Penciptaan Karya Komik Alternatif.Jurnal Pendidikan Seni Rupa, 3(2), 2015,16.

${ }^{11}$ Mediawati, E,Pembelajaran Akuntansi Keuangan Melalui Media Komik Untuk Meningkatkan Prestasi Mahasiswa. Jurnal Penelitian Pendidikan, 12(1), 2011, 63 
karakteristik dari segala subjek yang mampu memperkaya setting cerita, baik aspek wujud, gesture, maupun unsur imaji suara. ${ }^{12}$

Kemudian menurut Daryanto komik didefinisikan sebagai bentuk kartun yang mengungkapkan karakter dan menerapkan suatu cerita dalam urutan yang erat hubungannya dengan gambar dan dirancang untuk memberikan hiburan kepada pembaca. Pada awalnya komik diciptakan bukan untuk kegiatan pembelajaran, namun untuk kepentingan hiburan semata ${ }^{13}$.

\section{Semiotika Roland Barthes}

Roland Barthes dikenal sebagai tokoh naratologi postruktural Perancis dan juga dikenal sebagai semiolog yang sangat aktif dalam memanfaatkan teori Levi-Strauss, Michel Foucault, dan Jacques Lacan. ${ }^{14}$ Roland Barthes sangat dikenal luas sebagai penulis yang menggunakan analisis semiotik dan pengembang pemikiran pendahulunya seorang bapak semiologi atau semiotik Ferdinand de Saussure. Barthes, lahir di Chevourg pada tahun 1915 dan meninggal di Paris pada tahun 1980. Barthes hidup dikalangan keluarga kelas menengah Protestan di Cherbourg dan dibesarkan di Bayonne, kota kecil dekat pantai atlantik di sebelah barat daya Perancis. ${ }^{15}$ (Pawito, 2007, hlm. 163). Barthes belajar sastra Perancis dan bahasa-bahasa klasik di Universitas Paris, dan setelah lulus mengajar bahasa Perancis di Universitas Rumania dan Mesir, kemudian bergabung dalam Pusat Riset Ilmiah Nasional, mendalami bidang sosiologi serta leksikologi. Selain itu, Barthes juga mengajar sosiologi tanda, simbol dan representasi kolektif di Perancis. Ia memulai kariernya sebagai penulis kemudian mengabdikan dirinya pada semiologi. ${ }^{16}$

Menurut Barthes semiologi adalah ilmu yang mempelajari bagaimana kemanusiaa (humanity) memaknai hal-hal (things). Memaknai berarti, bahwa objek-objek tersebut tidak hanya membawa informasi, tetapi juga mengkonstitusikan sistem terstruktur dari tanda. Barthes melihat signifikasi sebagai sebuah proses yang total dengan suatu susunan yang telah terstruktur. Barthes menganggap signifikasi tak terbatas pada bahasa, tetapi juga pada hal-

\footnotetext{
${ }^{12}$ Ibid.

${ }^{13}$ Nurul Hidayah, Rifky Khumairo Ulva, Pengembangan Media Pembelajaran Berbasis Komik Pada Mata Pelajaran Ilmu Pengetahuan Sosial Kelas IV MI Nurul Hidayah Roworejo Negerikaton Pasawaran. Jurnal Pendidikan dan Pembelajaran Dasar, 4(1), 2017, 36

${ }^{14}$ Nyoman Kutha Ratna, Teori, Metode, dan Teknik Penelitian Sastra, Vol. 7, Yogyakarta: 2010, Pustaka Pelajar, 259

${ }^{15}$ Pawito,Penelitian Komunikasi Kualitatif. (Yogyakarta: 2007, LKiS Pelangi Aksara, 163
}

${ }^{16}$ Alfionita Rizky Perdana, Review Film Jihad Selfie, dalam https://www.academia.edu, diakses pada 13 Agustus 2019 
hal lainnya. Dengan demikian, kehidupan sosial atau apapun bentuknya merupakan suatu sistem tanda sendiri.

Fokus perhatian Barthes tertuju pada gagasan tentang signifikasi dua tahap (two order of signification), yaitu denotasi dan konotasi.
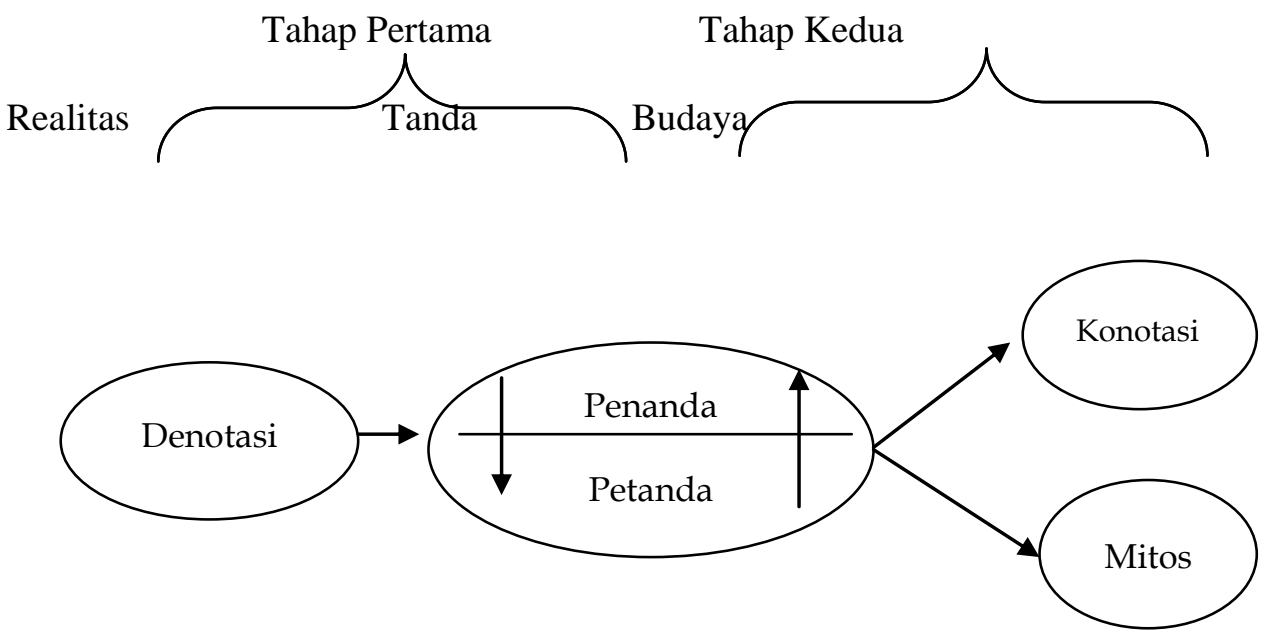

Dari gambar di atas, dapat dijelaskan bahwa signifikasi tahap pertama merupakan hubungan antara penanda dan petanda dalam sebuah tanda terhadap realitas eksternal. Barthes menyebutnya denotasi. Denotasi merupakan makna awal utama dari sebuah tanda, teks, dan sebagainya. Pada tahap ini menjelaskan relasi antara penanda dan petanda di dalam tanda, dan diantara tanda dengan objek yang diwakilinya dalam realitas. Denotasi merujuk pada apa yang diyakini akal sehat orang banyak, makna yang teramat dari sebuah tanda. Sedangkan konotasi merupakan makna subjektif. Hal ini menggambarkan interaksi yang terjadi ketika tanda bertemu dengan perasaan atau emosi dari pembaca dan nilai-nilai di dalam budaya mereka. Pada signifikasi tahap kedua yang berhubungan dengan isi, tanda bekerja melalui mitos. Hal ini sejalan dengan pendapat Arthur Asa Berger yang menyatakan, bahwa kata konotasi melibatkan simbol-simbol, historis, dan hal-hal lain yang berhubungan dengan emosional. ${ }^{17}$. Hal ini menggambarkan interaksi yang terjadi ketika tanda bertemu dengan perasaan atau emosi dari pembicaraaan serta nilai-nilai kebudayaan. Istilah inilah yang digunakan Barthes untuk menunjuk signifikasi tahap kedua. Pada tatanan tahap kedua (konotasi) berhubungan dengan isi, tanda bekerja melalui mitos (myth). Mitos merupakan lapisan makna dan petanda yang paling dalam. Mitos adalah sebuah cerita dimana suatu kebudayaan menjelaskan atau memahami beberapa aspek dari realitas atau alam. Mitos ini berfungsi untuk

${ }^{17}$ Alex Sobur, Semiotika Komunikasi, (Bandung: Remaja Rosdakarya, 2003), 
mengungkapakan dan memberikan pembenaran terhadap nilai-nilai dominan yang berlaku dalam suatu periode tertentu. ${ }^{18}$

\section{Analisis DisorientasiMakna Jihad Dalam Komik Jihad Selfie}

\section{Penyajian Data}

Pada bab ini, penulis akan memaparkan data yang ditemukan untuk dianalisis. Karena fokus penelitian penelitian ini adalah mencari disorientasi makna jihad dalam komik Jihad Selfie, maka data yang penulis paparkan hanyalah imagiyang mengandung disorientasi makna jihad saja.Setelah memahami disorientasi makna jihad dan konsepnya, penulis melakukan observasi pada komik Jihad Selfie, dan menemukan beberapaimagiyang mengandung disorientasi makna jihad di dalamnya. Berikut merupakan imagiyang mengandung disorientasi makna jihad yang ditemukan penulis:

\section{Imagi 1}

\begin{tabular}{|c|c|}
\hline \multicolumn{2}{|r|}{ Gambar } \\
\hline & 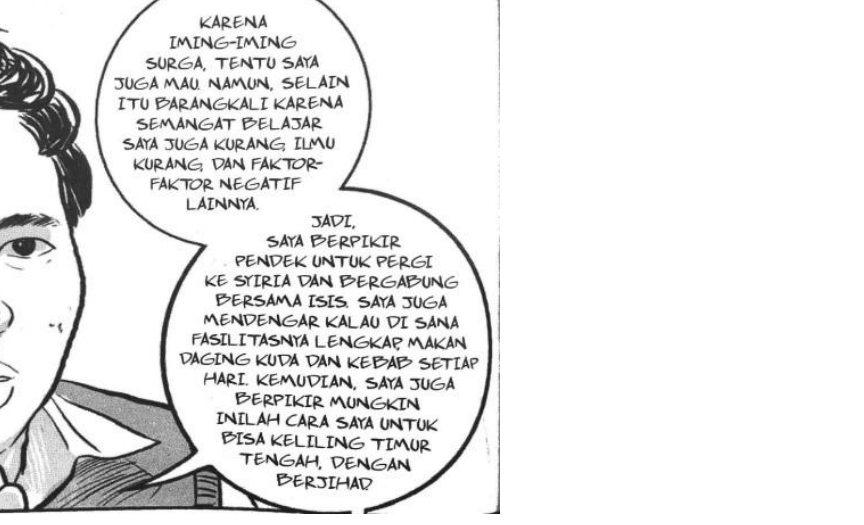 \\
\hline Ekspresi Wajah & $\begin{array}{l}\text { Berpikir dan membayangkan fasilitas-fasilitas enak } \\
\text { yang disediakan ISIS }\end{array}$ \\
\hline Balon kata & ( \\
\hline Balon pikiran & $\begin{array}{l}\text { "Karena iming-iming surga, tentu saya juga mau. } \\
\text { Namun, selain barangkali karena semangat belajar saya } \\
\text { juga kurang, ilmu kurang, dan faktor-faktor } \\
\text { lainnya.Jadi, saya berfikir pendek untuk pergi ke Syiria } \\
\text { dan bergabung bersama isis. Saya juga mendengar } \\
\text { disanafasilitasnya lengkap, makan daging kuda dan } \\
\text { kebab setiap hari. Kemudian, saya juga berpikir } \\
\text { mungkin inilah cara saya untuk bias keliling timu } \\
\text { tengah untuk berjihad" }\end{array}$ \\
\hline
\end{tabular}

${ }^{18}$ Ibid., 71 


\begin{tabular}{|l|l|}
\hline Efek bunyi & - \\
\hline Latar & - \\
\hline
\end{tabular}

\section{Imagi 2}

Balon kata

\section{Imagi3}




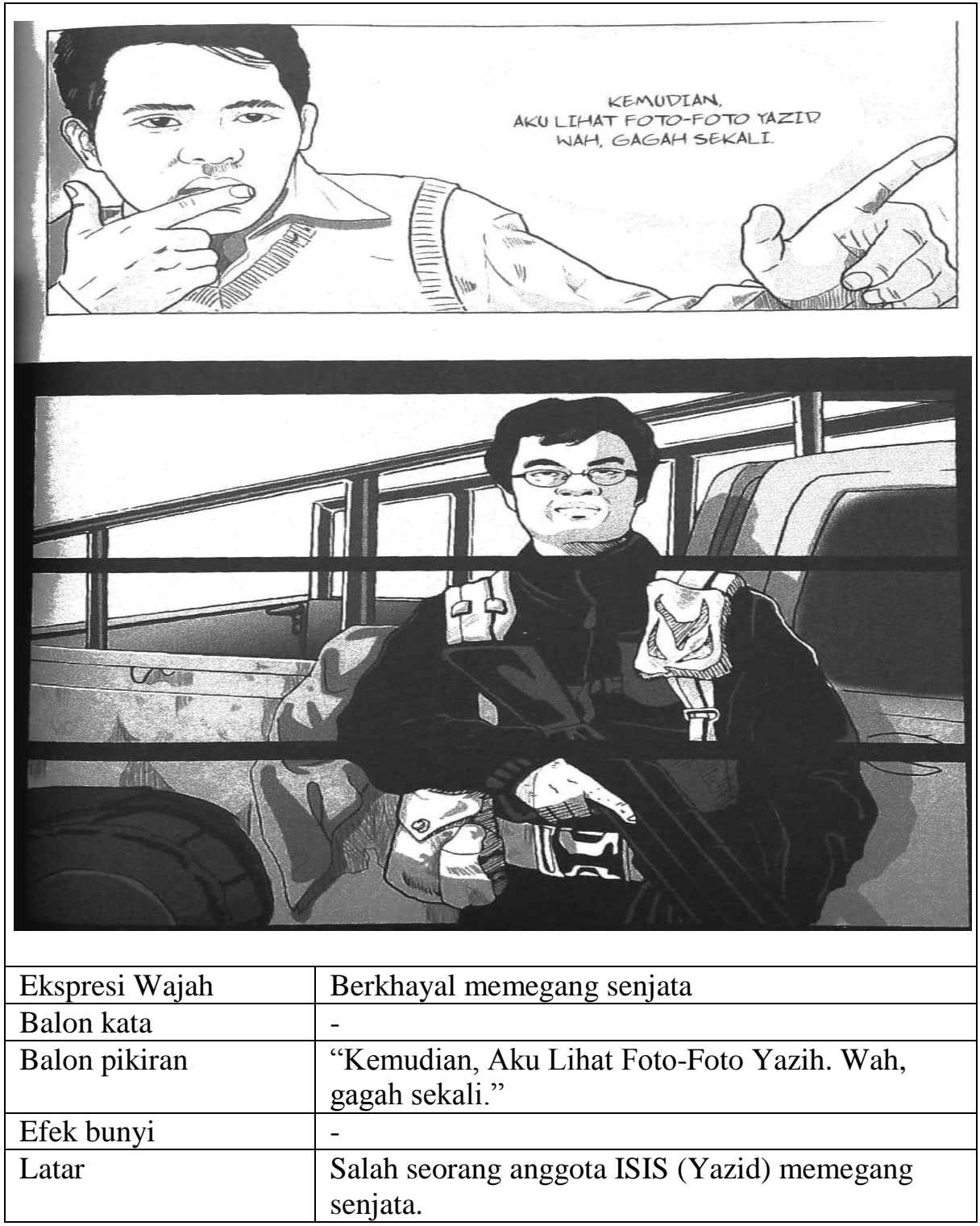

\section{Imagi 4}




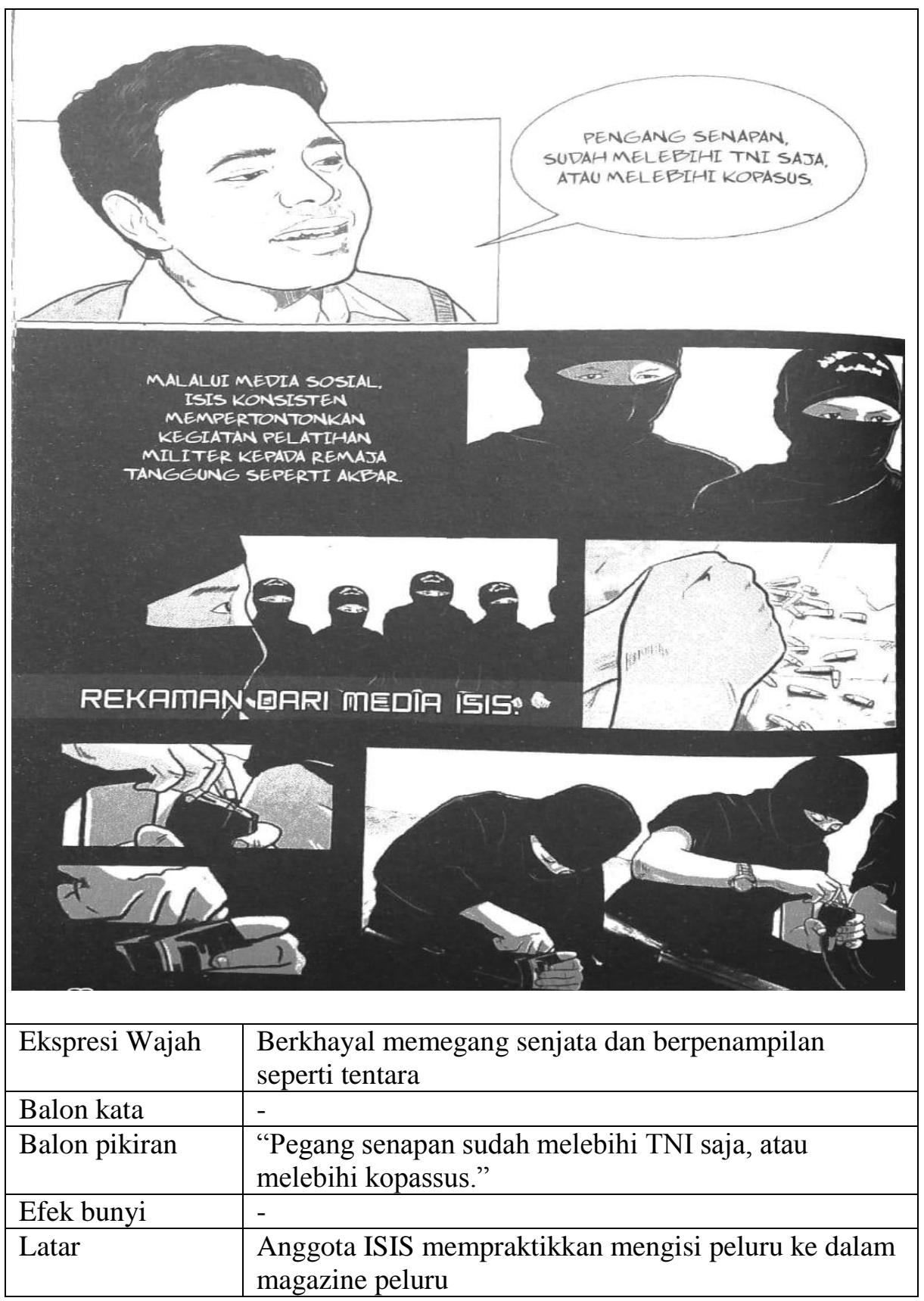

\section{Temuan Penelitian}


Pada tahap ini, peneliti akan mencoba untuk menganalisis data yang sudah dipilih sesuai dengan fokus penelitian dengan menggunakan analisis semiotik model Roland Barthes. Selanjutnya peneliti akan mengelompokkan data yang akan dianalisis menjadi dua tahapan analisis yaitu denotatif dan konotatif.

\section{Imagi 1}

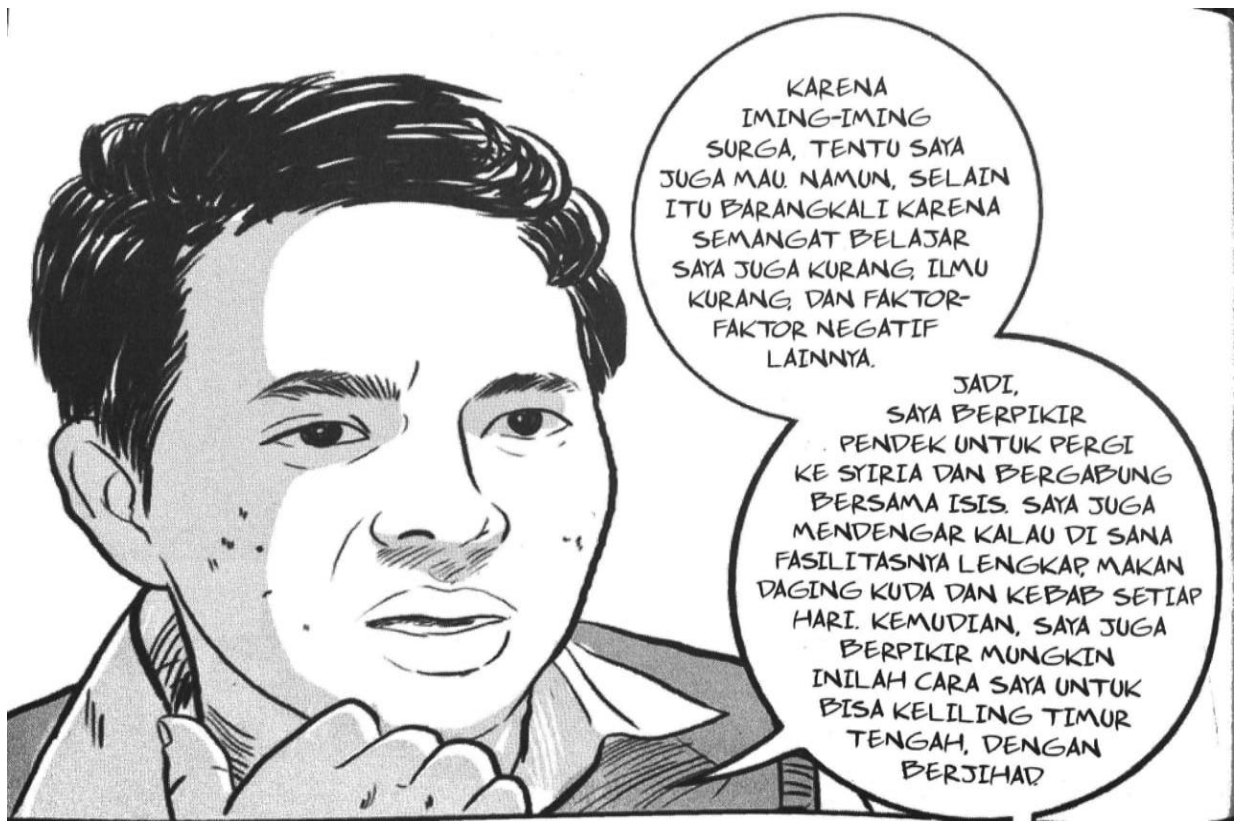

\section{Makna Denotatif}

Teukur Akbar Maulana, tokoh utama dalam komik Jihad Selfie ini berniat pergi ke Syiria karena dijanjikan akan masuk surga dan diberikan fasilitas lengkap, dengan cara pergi ke Syiria, Teuku Akbar Maulana berharap bisa mengelilingi dunia khususnya jazirah Arab.

\section{Makna Konotatif}

Propaganda-propaganda Islamic State of Irak and Syiria (ISIS) di media sosial membuat Teuku Akbar Maulana lupa bahwa tujuannya ke Turki adalah untuk belajar agama di Imam Katip High School. Teuku Akbar tergoda karena dijanjikan akanmendapatkan fasilitas lengkap jika bergabung dengan ISIS, seperti makanan yang enak dan sebagainya. Jika gugur di medan peran, ia dijanjikan akan mati sebagai seorang syuhada dengan balasan surga.

Karena diiming-imingi surga, persepsi Teuku Akbar terhadap dirinya sendiri pun nyaris berubah, ia menganggap dirinya tidak punya semangat belajar dan ilmunya kurang, sehingga yang ada dipikirannya adalah bergabung dengan ISIS lebih menguntungkan dari pada belajar di Imam Katib High School. 
Khayalan Teuku Akbar semakin melambung tinggi, karena menyangka bergabung dengan ISIS berarti membuka peluang baginya untuk mengelilingi seluruh daerah di Timur tengah sambil berjihad.

\section{Imagi 2}

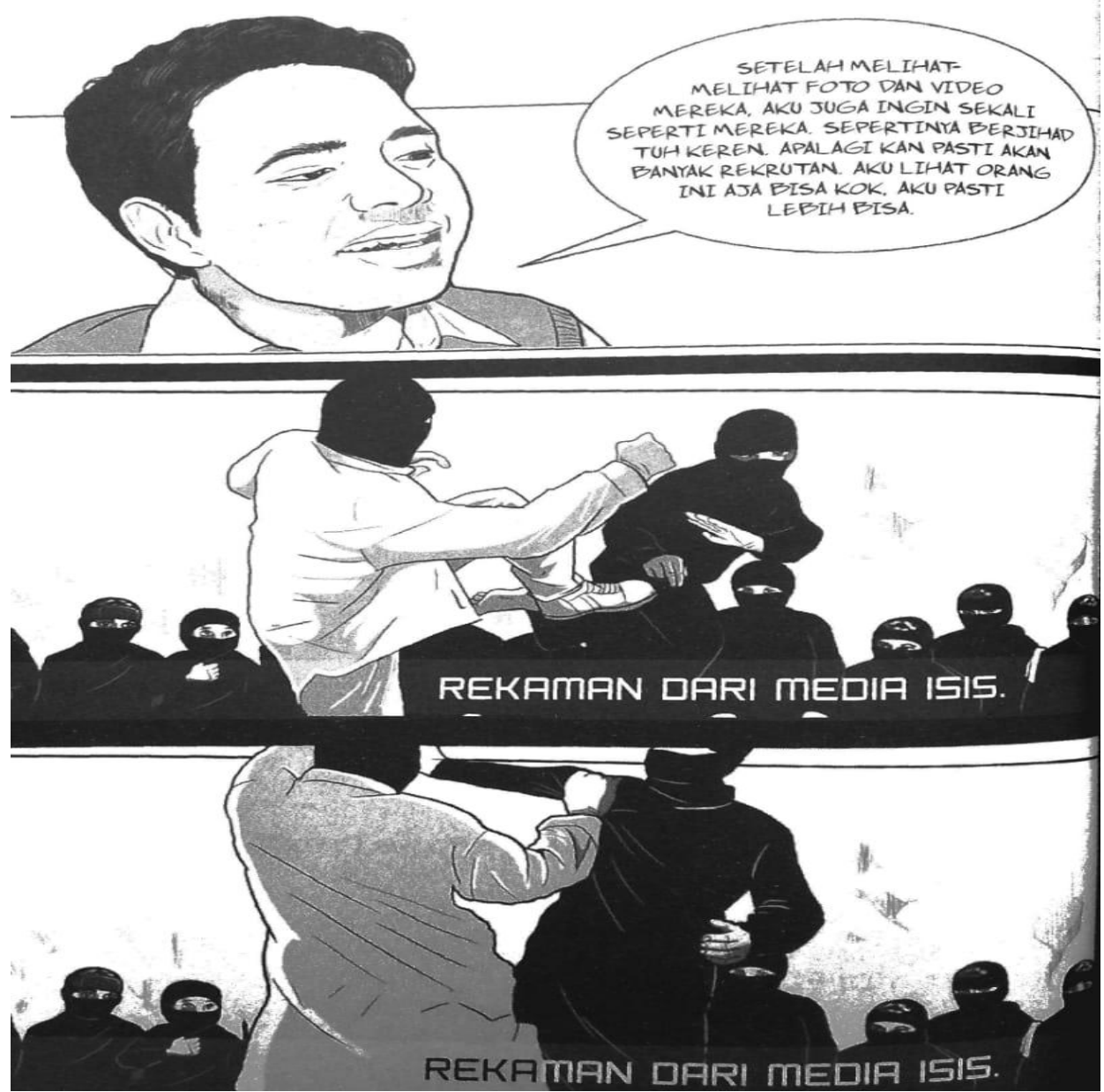

\section{Makna Denotatif}

Teuku Akbar Maulana ingin menjadi bagian dari ISIS karena baginya latihan bela diri, pakaian militer dan berjihad di medan perang adalah sesuatu yang keren. Teuku Akbar beranggapan bahwa ia juga bisa menjadi seperti anggota ISIS (berlatih bela diri, memakai pakaian militer dan berjihad).

\section{Makna Konotatif}


Karakteristik militer yang menonjolkan keterampilan bela diri, kekuatan, kejantanan, keberanian, ketangguhan, mampu memproyeksikan rasa hormat dan takut pada masyarakat, begitu juga dengan pakaian militer.

Pakaian merupakan salah satu kebutuhan primer yang harus dipenuhi oleh manusia. Dengan dipenuhinya pakaian sebagai kebutuhan primer, maka pakaian memiliki nilai lebih bagi penggunanya yaitu sebagai alat untuk mengekspresikan dirinya di masyarakat. Hal ini menunjukkan bahwa pakaian memiliki fungsi lebih yaitu sebagai alat untuk menyampaikan pesan non verbal, pernyataan status dan kelas sosial, dan pembentukan identitas kolektif berupa penggunaan busana yang seragam dengan anggota kelompok.

Oleh karena itu, melalui keterampilan bela diri dan pakaian militer, Teuku Akbat Maulana ingin menunjukkan bahwa ia "keren dan kuat" dan seperti seorang tentara.

\section{Imagi 3}

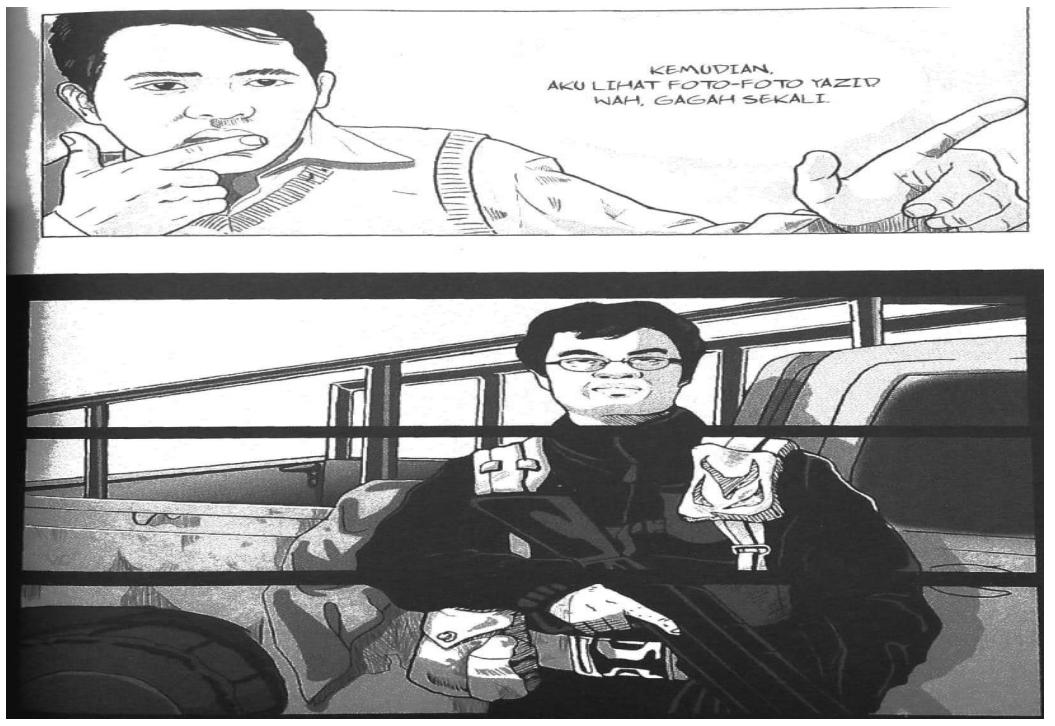

\section{Makna Denotatif}

Seseorang memegang senjata api laras panjang dan memakai atribut militer dianggap gagah oleh Teuku Akbar Maulana

\section{Makna Konotatif}

Pemegang senjata adalah Yazid, orang Indonesia yang berhasil direkrut oleh ISIS dan kemudian menjadi alat propaganda mencari pengikut baru di Indonesia. 


\section{Imagi 4}

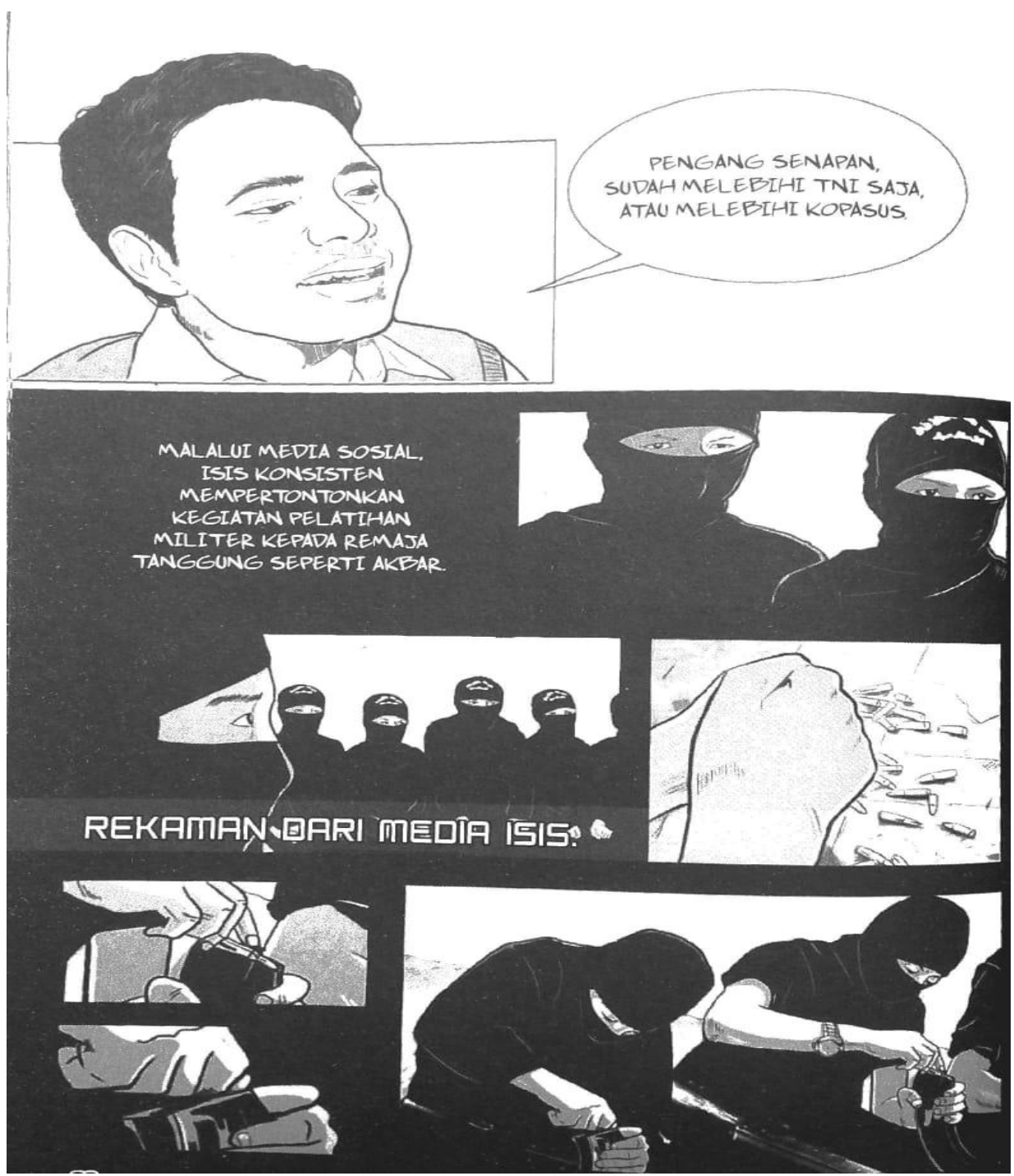

\section{Makna Denotatif}

Teuku Akbar Maulanamembayangkan jika dia memegang senjata, dia akan terlihat seperti anggota TNI, bahkan lebih gagah dari anggota TNI.

\section{Makna Konotatif}

Anggota ISISsedang berlatih mengasah keterampilan mengisi peluru ke magazin.Pakaian, senjataa dan atribut yang digunakan anggota ISIS lebih terlihat "garang" dibandingkan anggota TNI. 


\section{Penutup}

Pengertian jihad harus benar-benar dipahami oleh semua pihak agar tidak terjadi salah paham atar umat beragama khususnya agama Islam dengan agama lainnya karena akhir-akhir ini banyak pihak yang menganggap bahwa jihad merupakan sebuah tindakan yang radikal dan bahkan di sebut dengan aksi terorisme oleh kaum non-Islam, hal tersebut pastilah menyudutkan seluruh kaum Islam dalam kehidupan bermasyarakat. Dalam umat Islam arti kata jihad pun harus dicerna dengan baik agar kita sebagai umat Islam tidak menyalah artikan kata tersebut yang dampaknya justru akan menjadi buruk dan tidak sesuai syariat Islam khususnya jihad.

Penelitian tentang disorientasi makna jihad dalam komik jihad selfie dengan menggunakan pendekatan semiotika Roland Barthes ini menghasilkan gambaran beberapa bentuk penyimpangan makna jihad diantaranya sebagai berikut; (1) Jihad identik dengan senjata, (2) Dengan memegang senjata dan atribut militer lainnya akan terlihat seperti anggota TNI bahkan legih gagah dari anggotaTNI (3) Jihad bisa membawa pelakunya mengelilingi kota-kota di Timur Tengah, (4)Terdapat berbagai fasilitas yang mewah bagi para mujahid. 


\section{Daftar Pustaka}

Abdul Karim Batubara."Distorsi Pesan dalam Perpustakaan”.Iqra': Jurnal Perpustakaan dan Informasi, Vol. 9, No. 2 (2015)

Alex Sobur. Semiotika Komunikasi. Bandung: Remaja Rosdakarya, 2003.

Alex Sobur. Analisis Teks Media.Bandung: Remaja Rosdakarya, 2004.

Alfionita Rizky Perdana. Review Film Jihad Selfie, dalam https://www.academia.edu, diakses pada 13 Agustus 2019

Bambang Purwanto, Sejarawan Akademik dan Disorientasi Historiografi: Sebuah Otokritik. (Dipresentasikan pada Rapat Terbuka Majelis Guru Besar Universitas Gadjah Mada, Yogyakarta, 2004)

Disorientasi Pemikiran, 2014, dalam https://www.abualbanicentre.com, diakses 14 September 2018

Dwi Nugroho Mukti dan Salamun. "Penciptaan Karya Komik Alternatif”.Jurnal Pendidikan Seni Rupa, Vol. 3, No. 2, (2015)

Elis Mediawati.“Pembelajaran Akuntansi Keuangan Melalui Media Komik Untuk Meningkatkan Prestasi Mahasiswa".Jurnal Penelitian Pendidikan, Vol. 12, No. 1, (2011)

Nurul Hidayah dan Rifky Khumairo Ulva, "Pengembangan Media Pembelajaran Berbasis Komik Pada Mata Pelajaran Ilmu Pengetahuan Sosial Kelas IV MI Nurul Hidayah Roworejo Negerikaton Pasawaran".Jurnal Pendidikan dan Pembelajaran Dasar, Vol. 4, No. 1, (2017)

Nyoman Kutha Ratna.Teori, Metode, dan Teknik Penelitian Sastra. Yogyakarta: Pustaka Pelajar, 2010.

Pawito. Penelitian Komunikasi Kualitatif. Yogyakarta:LKiS Pelangi Aksara, 2007.

Rif’at Husnul Ma'afi.“Konsep Jihad Dalam Perspektif Islam”.Kalimah: Jurnal Studi Agama dan Pemikiran Islam, Vol. 11, No. 1, (2013)

Suharsimi Arikunto. Prosedur Penelitian Suatu Pendekatan Praktek. Jakarta: Rineka Cipta, 2002.

Gangguan Semantik dalam Komunikasi, 2018, dalam https://pakarkomunikasi.com, diakses pada 18 Agustus 2019 